\section{Management of Diamondback Moth (Lepidoptera: Plutellidae) in Cabbage Using Collard as a Trap Crop}

\author{
E.R. Mitchell \\ Centerfor Medical, Agricultural, and Veterinary Entomology, U.S. Department \\ of Agriculture, Agricultural Research Service, P.O. Box 14565, Gainesville, \\ FL 32604

\section{Guangye Hu and Denise Johanowicz \\ Department of Entomology and Nematology, University of Florida, P.O. Box 110620, Gainesville, FL 32611}

Additional index words. cultural control, Diadegma insulare, integrated pest management, IPM, natural enemy conservation, cabbage looper, Brassica oleracea, Plutella xylostella, Trichoplusia $n i$

\begin{abstract}
Collard greens (Brassica oleracea var. acephala L.) were planted in the peripheries of cabbage (Brassica oleracea var. capitata $L$.) fields in the spring growing seasons of 1997 and 1998 to evaluate their effectiveness as a trap crop to manage the diamondback moth (DBM) [Plutella xylostella (L.)]. The numbers of DBM never exceeded the action threshold for application of insecticides in any of the fields that were completely surrounded by collards, but did exceed the action threshold in three of the fields without collards on four sampling dates in 1998. In both years, the numbers of DBM larvae in the collards exceeded the action threshold of 0.3 total larvae/plant in eight of nine fields. Larval counts in cabbage surrounded with collards were not significantly higher than in the conventionally planted cabbage, even though the number of pesticide applications was reduced in the former. The few pesticide applications in fields surrounded by collards probably targeted the cabbage looper [Trichoplusia ni (Hübner)], which was not impeded by the collards from infesting the interior cabbage. There was no significant reduction in marketability, and damage to cabbage was similar to that in fields where collards were planted and in fields where only conventional pesticides were used. The reduced number of pesticide sprays, as well as the high concentration of host larvae in the collards, may help maintain populations of natural enemies of DBM in the agroecosystem. Planting collards in field peripheries is a potentially effective tactic to manage DBM in cabbage.
\end{abstract}

Cruciferous vegetables are important crops throughout the world, comprising up to $25 \%$ of the land devoted to vegetable planting in some areas (Talekar et al., 1992). The diamondback moth (DBM) has become the most destructive pest of crucifers, occurring wherever they are planted, and costs to manage it are $\approx \$ 1$ billion annually (Talekar et al., 1992). The DBM is difficult to control, in part because it has developed resistance to many chemical insecticides, as well as resistance to Bacillus thuringiensis in some populations (Kirsch and Schmutterer, 1988; Tabashnik et al., 1990). The difficulty of controlling this pest has forced some growers to abandon the

Received for publication 27 July 1999. Accepted for publication 21 Dec. 1999. We thank Joyce Leach Bill Copeland, Richard Furlong, Jeff Coleman, Jennifer Gillett, James Okine, and Doug Sieglaff for technical assistance; and T. Turner, R. Hawkins, Q. Emery, R. Mitchell, L. Corn, and D. Johnston and Sons, cabbage growers without whose cooperation and understanding this study would not have been possible. The cost of publishing this paper was defrayed in part by the payment of page charges Under postal regulations, this paper therefore must be hereby marked advertisement solely to indicate this fact. Shelton, 1993; Talekar et al., 1992).

Because of the major importance of this pest and the development of resistance to a wide range of insecticides, the adoption of an integrated pest management (IPM) strategy is necessary in order to reduce populations of DBM in cruciferous crops below economic injury levels (see, for example, Talekar and Shelton, 1993). In cabbage, IPM has been implemented for some time, and currently efforts are underway to improve it. Integrated pest management of DBM has been attempted in many countries with varying degrees of success (reviewed by Lim, 1992).

In the United States, an IPM approach to control lepidopterous pests in cabbage is being implemented on a limited basis in a number of areas, for example, in the Rio Grande Valley of Texas (Biever et al., 1994). In Florida, an IPM program recently has been under trial for control of DBM in cabbage fields. This program uses a combination of tactics, such as biological control (release of parasitoids; Mitchell et al., 1997a), pheromones for disrupting mating (Mitchell et al., 1997b), Bt pesticides, and trap crops (Mitchell et al., 1997c).

Indian mustard [Brassica juncea (L.)] has been evaluated as a trap crop to protect cab- production of cruciferous crops (Talekar and bage from the DBM in India (Srinivasan and Krishna Moorthy, 1992), Guam (Silva-Krott et al., 1995), and the United States (Bender et al., 1999; Luther et al., 1996), because it is reportedly a more attractive plant for DBM oviposition than is cabbage (Srinivasan and Krishna Moorthy, 1991). Although Srinivasan and Krishna Moorthy (1992) report success with this tactic, it was unsuccessful in the other three studies. Two possibilities for these failures could have been that the experimental field plots were too small or the cultivars differed, both of which may interfere with olfactory cues important in oviposition.

Studies have shown that collard greens also harbor higher numbers of DBM larvae than do many other cultivated crucifers, including cabbage (Harcourt, 1957). One practical benefit of using collard greens as a trap crop as opposed to Indian mustard is that collards can be planted at the same time as cabbage and last the duration of the cabbage season; whereas the rapid senescence of mustard requires two to three plantings during the cabbage growing season (Bender et al., 1999; Srinivasan and Krishna Moorthy, 1992).

A previous study demonstrated that DBM populations built up in collards that were stripplanted in the center of cabbage fields, but did not infest the adjacent cabbage (Mitchell et al., 1997c). The DBM initially infests cabbage fields along the peripheries, and moves toward the field interior later in the season (Hu et al., 1997). Therefore, planting collards as a trap crop in the field peripheries may impede the DBM from infesting the interior cabbage.

The purpose of this 2-year study was to determine the efficacy of planting collards in the peripheries of cabbage fields as a trap crop to manage DBM. Because perturbations to an ecosystem may have qualitatively different effects depending on the size of the plots (Carpenter, 1990; George et al., 1992), fullsize commercial cabbage fields were examined to avoid any potential problems associated with small plots, as well as to study this system under common production conditions. Larval counts, damage to and marketability of the cabbage, and the number of pesticide applications in various field sizes and locations were compared for cabbage with and without collard trap crops.

\section{Materials and Methods}

1997. A total of five commercial cabbage fields near Bunnell, Flagler County, Fla., was used in the study. 'Bravo' cabbage seedlings were planted 2-6 Feb. 1997, and 'Vates' collard seedlings were transplanted in the peripheries of three fields. Two rows of collard plants were planted along each side and seven collard plants were planted on the ends of each row (Figs. 1 and 2). Each of the two control fields (fields 1 and 2, cabbage plants only) was 12.0 ha in area. The collard-surrounded fields (3, 4, and 5) were 10.0, 12.4, and 5.1 ha, respectively. Cabbage and collard plants were planted in rows $0.76 \mathrm{~m}$ apart with $0.23-\mathrm{m}$ plant spacing. The distance between the collardsurrounded and control fields was $\approx 1.5 \mathrm{~km}$. 
Diamondback moth and cabbage looper larvae were sampled from cabbage and collard plants weekly throughout the growing season. Each sample consisted of 14 plants, seven in each of two adjacent rows. Nine sampling sites were chosen in the interior of each field (Fig. 2). Six sites were equally spaced and arranged in two separate rows across the field, each row starting at a point one-third the distance in from the sides and ends of the field, respectively. In addition, three sites were selected near the center of the field. These sites were equally spaced and aligned along a row, starting one-fourth the distance in from the row's ends. Six sampling sites also were selected for collard plants growing in field margins. Two sites were located along each side of the field opposite the interior cabbage sampling sites, and one at each end of the row opposite the interior sampling sites located near the center of the field. The average ( \pm SE) DBM larval counts on cabbage and collard plants were compared using a two-sample $t$ test (SAS Institute, 1990) on each date for each field. The raw numbers of larval counts per plant were transformed to $\sqrt{n+1}$ to meet the assumptions of the $t$ test before performance of the analysis (Marks, 1990).

1998. A more extensive study was conducted in 12 commercial cabbage fields, six near Bunnell, Flagler County, Fla., and six near Palatka, Putnam County, Fla. Cabbage seedlings were planted 10 Oct. 1997-10 Jan. 1998 at Palatka, and 5-26 Jan. at Bunnell. Collard greens were transplanted in the peripheries of three fields as described for 1997. The areas of the three control fields (fields 1, 2 , and 3 , cabbage plants only) were 8.0, 6.1, and 4.9 ha, respectively. The collard-surrounded fields $(4,5$, and 6$)$ were $6.0,4.0$, and 8.1 ha, respectively. The areas of the three control fields at Bunnell (7, 8, and 9, cabbage plants only) were 12.0 ha each. The areas of the collard-surrounded fields (10,11, and 12) were $8.5,12.1$, and 5.1 ha, respectively.

Diamondback moth and cabbage looper larvae were sampled from the cabbage and collard plants weekly throughout the growing season. Each sample site consisted of 10 plants, five in each of two adjacent rows. Four sampling sites were chosen in the interior of each field (Fig. 2). Two sites were arranged in a row starting one-third the distance in from each side and the ends of the rows. Four sampling sites also were selected for collard plants growing in field margins. One sample site was located equidistant along the length and breadth of the field, except for field 10, which had three collard sites, and field 12, which had two cabbage and two collard sites. The average ( \pm SE) DBM larval counts on cabbage and collard plants were compared using a two-sample $t$ test (SAS Institute, 1996) on each date for each field. The raw numbers of larval counts per plant were again transformed to $\sqrt{n+1}$ before statistical analysis. The mean numbers of DBM larvae in cabbage in all of the fields were compared using Tukey-Kramer HSD at $P$ $\leq 0.05$ (SAS Institute, 1996).

When possible, cabbage damage ratings were assessed immediately prior to harvest.

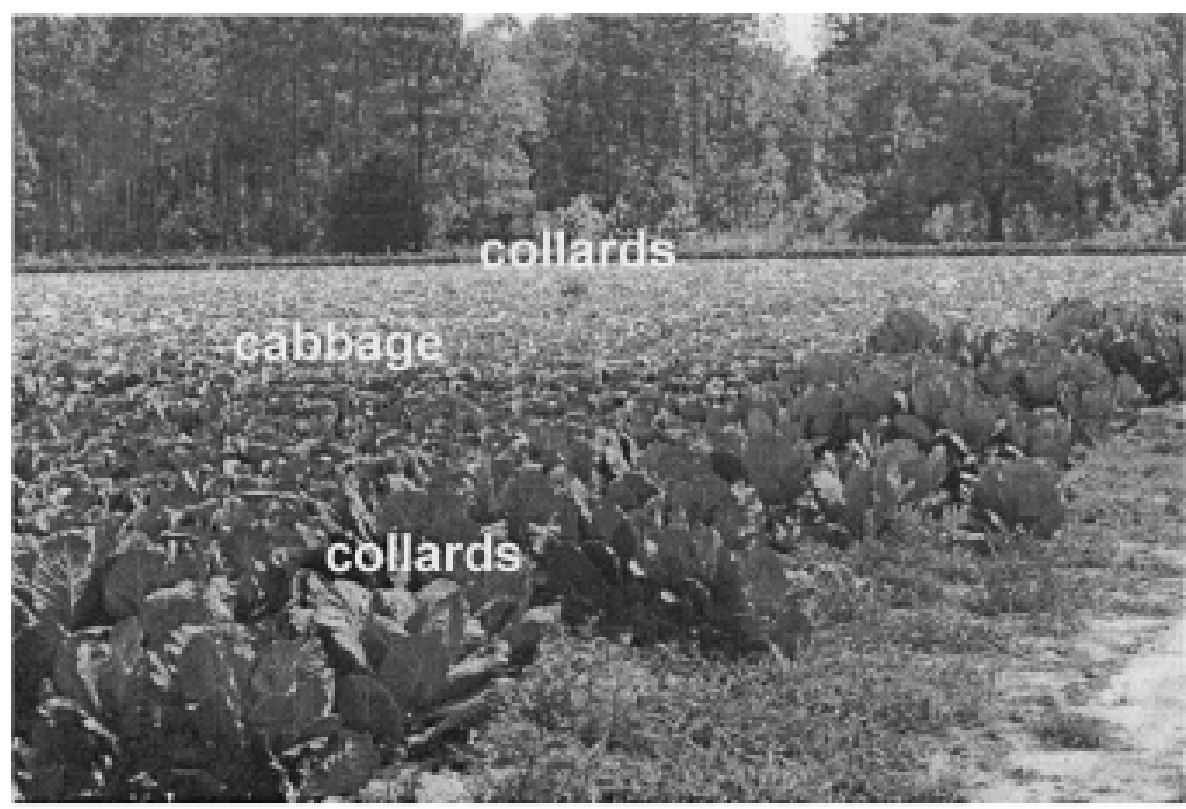

Fig. 1. Collard greens planted as a trap crop for diamondback moth (DBM) in the margins of cabbage fields. Seven collard plants were planted on the ends of rows (foreground), and two rows of collards were planted along each side of the field (background). The plants at rows' end were transplanted by hand; the collards along the sides of the field were planted with a 4-row, tractor-drawn machine designed to set cabbage transplants. All collards were planted at the same time as the cabbage and remained attractive throughout the growing season.

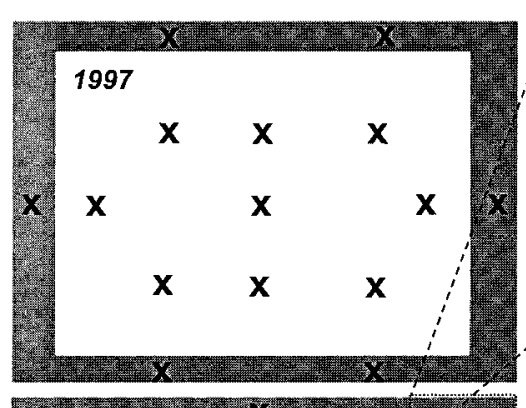

\section{2 rows of collards}

1998
$\mathbf{X}$

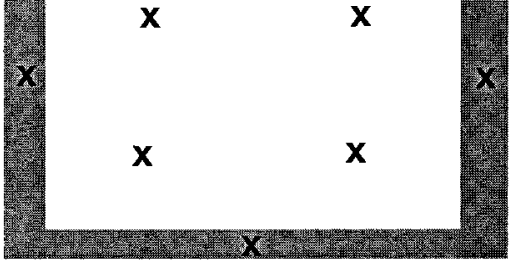

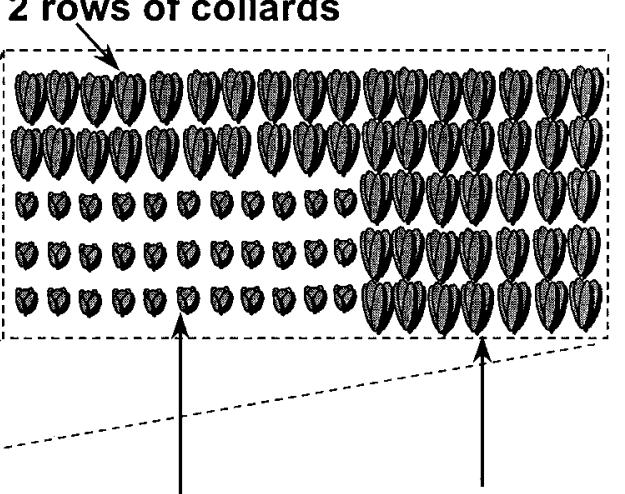

7 collard plants

\section{cabbage}

Fig. 2. Schematic diagram of sampling and trap crop planting design used in 1997 and 1998. Sampling sites are indicated with an "x." Control fields were sampled in a similar manner except for the sites in the collard regions, where no sampling took place.

Ratings were based on a scale of 1-6 (Greene et al., 1969; Leibee, 1996), where $1=$ no damage to the head and four wrapper leaves, and $6=$ maximum damage that rendered the head unacceptable for commerce. A head with a rating of 1-3 (no damage to head) generally is considered marketable. The mean damage ratings were combined for each grower (fields 4 and $5=$ Grower $1 \mathrm{a} ; 6=$ Grower $1 \mathrm{~b}$ ) (Grower $1 \mathrm{a}=$ completely surrounded fields; Grower $1 \mathrm{~b}$ $=$ incompletely surrounded fields); (fields 10, 11 , and $12=$ Grower 2 ; field $8=$ Grower 3 ; field $9=$ Grower 4 ), and were compared using Tukey-Kramer HSD (SAS Institute, 1996). The resulting proportion of marketable heads was calculated, transformed to arcsin square root, and compared using Tukey-Kramer HSD (SAS Institute, 1996) at $P \leq 0.05$.

In both years, the growers were allowed to apply pesticides at their discretion, and in some cases, their decisions were based on the results of our weekly scouting reports. Pesticide application data were provided by the growers. 


\section{Results}

1997. Results from the three fields surrounded with collards were similar. Diamondback moth larval counts per cabbage plant remained $<0.1$ for fields 3 and 4 , and 0.15 for field 5 throughout the season. The larval counts on collard plants, however, increased dramatically in early and mid-March, peaked in midor late March with 0.8 larvae per plant for field 3, 0.9 for field 4 and 1.1 for field 5, and then declined. On seven sampling dates the numbers of DBM larvae on collard plants were significantly greater than those on cabbage plants (Table 1; data presented starts with week 6 of the study; few larvae were collected before this time). The larval counts per collard plant were higher than the action threshold for pesticide application (0.3 larvae per plant, Cartwright et al., 1987) in midseason in each field. When the numbers of DBM and cabbage looper larvae were combined, the counts reached the action threshold in each collardsurrounded field in midseason.

Larval counts per cabbage plant in two control fields were similar to those in the collard-surrounded fields. Diamondback larval counts remained under the action threshold of pesticide spray, but total counts for DBM and cabbage looper larvae exceeded the action threshold of pesticide application on weeks 8 , 10 , and 11 for field 1 , and weeks 7 and 11 for field 2 . Three pesticide applications were reported for fields 3,4 , and 5 and eight for fields 1 and 2.

1998. Results obtained in 1998 were similar to those in 1997. The number of DBM larvae/cabbage plant did not reach the action threshold in any of the fields completely surrounded by collards (Tables 2 and 3; data presented starts with week 8 of the study; few larvae were collected before this time). However, the action threshold was reached numerous times in the control fields. The only field with collards in which DBM larvae/cabbage that exceeded the action threshold was field 6; this field was incompletely surrounded by collards. Since DBM infestations generally start in the field margins (Hu et al., 1997), it is not surprising that the field with gaps in the collard plantings had higher infestation in the cabbage. The number of DBM larvae/collard plant often reached the action threshold in most fields. There was a trend for more DBM larvae/plant in the collards than in the cabbage, with significantly more in fields 5 (weeks 10 and 12) and 6 (week 10), 10 (week 13) and 11 (week 11). Even though fewer pesticide applications were made in the cabbage fields surrounded with collards (Fig. 3), there were never significantly more DBM larvae/cabbage plant than in the control fields. There were no significant differences in damage ratings (Fig. 3A) or the proportion of marketable heads (Fig. 3B) in the various growers' fields except for the incompletely surrounded field, even though the growers using the trap crops applied fewer sprays than did those using conventional control methods.

When combining counts for both DBM

Table 1. Effect of trap cropping cabbage with collards on mean number of larvae collected per plant in Bunnell, Fla., during weeks 6-11 in Spring 1997.

\begin{tabular}{|c|c|c|c|c|c|c|c|c|}
\hline \multirow{2}{*}{$\begin{array}{l}\text { Crop } \\
\text { sampled }\end{array}$} & \multirow{2}{*}{$\begin{array}{l}\text { Other } \\
\text { crop }\end{array}$} & \multirow[b]{2}{*}{ Field } & \multicolumn{6}{|c|}{ Week } \\
\hline & & & 6 & 7 & 8 & 9 & 10 & 11 \\
\hline & & & & $\mathrm{Mea}$ & $D B M$ & le/cabba & lant & \\
\hline \multirow[t]{6}{*}{ Cabbage } & None & 1 & 0 & 0.03 & 0.14 & 0.01 & 0 & 0 \\
\hline & None & 2 & 0.17 & 0.12 & 0 & 0.01 & 0.03 & 0 \\
\hline & Collards ${ }^{\mathrm{z}}$ & 3 & 0.07 & 0.01 & 0.03 & 0 & 0 & 0 \\
\hline & Collards ${ }^{\mathrm{z}}$ & 4 & 0.01 & 0.03 & 0.03 & 0 & 0 & 0 \\
\hline & Collards $^{\mathrm{z}}$ & 5 & 0.07 & 0.19 & 0.12 & 0.05 & 0 & 0 \\
\hline & & & \multicolumn{6}{|c|}{ Mean no. DBM larvae/collard plant } \\
\hline \multirow[t]{4}{*}{ Collards } & Cabbage & 3 & 0.21 & $0.73^{\mathrm{y}, \mathrm{x}}$ & $0.54^{y, x}$ & 0.11 & 0.11 & 0 \\
\hline & Cabbage & 4 & 0.21 & $0.91^{\mathrm{y}, \mathrm{x}}$ & 0.29 & 0.10 & 0.02 & $0.62^{y, x}$ \\
\hline & Cabbage & 5 & 0.04 & $0.63^{y, x}$ & $1.07^{\mathrm{y} \mathrm{x}}$ & $0.50^{y, x}$ & 0.11 & 0.08 \\
\hline & & & & \multicolumn{5}{|c|}{ Mean no. $D B M+C L$ larvae/cabbage plant } \\
\hline \multirow[t]{6}{*}{ Cabbage } & None & 1 & 0.01 & 0.10 & $0.33^{\mathrm{x}}$ & 0.09 & $0.46^{\mathrm{x}}$ & $0.47^{\mathrm{x}}$ \\
\hline & None & 2 & 0.27 & $0.36^{x}$ & 0.24 & 0.17 & 0.17 & $0.36^{x}$ \\
\hline & Collards ${ }^{\mathrm{z}}$ & 3 & 0.16 & $0.41^{x}$ & $0.36^{x}$ & $0.34^{x}$ & 0.21 & 0 \\
\hline & Collards ${ }^{\mathrm{z}}$ & 4 & 0.06 & $0.41^{x}$ & $0.57^{x}$ & 0.14 & 0.27 & 0.17 \\
\hline & Collards $^{\mathrm{z}}$ & 5 & 0.10 & 0.24 & 0.19 & $0.31^{\mathrm{x}}$ & 0.17 & 0.10 \\
\hline & & & \multicolumn{6}{|c|}{ Mean no. $D B M+C L$ larvae/collard plant } \\
\hline \multirow[t]{3}{*}{ Collards } & Cabbage & 3 & 0.24 & $1.05^{\mathrm{x}}$ & $0.93^{x}$ & $0.30^{\mathrm{x}}$ & $0.38^{x}$ & 0 \\
\hline & Cabbage & 4 & $0.32^{x}$ & $1.03^{x}$ & $0.36^{x}$ & 0.19 & 0.19 & $0.88^{x}$ \\
\hline & Cabbage & 5 & 0.05 & $0.73^{x}$ & $1.32^{x}$ & $0.96^{x}$ & 0.27 & 0.14 \\
\hline
\end{tabular}

${ }^{\mathrm{z}}$ Cabbage plots were surrounded by collards in these fields.

${ }^{\mathrm{y}}$ Mean number of larvae/plant in collards significantly different from number in cabbage in the same field (i.e., Field 3, 4, or 5) using a two-sample $t$ test at $P \leq 0.05$.

${ }^{x}$ Number of larvae at or above action threshold of 0.3 total larvae/cabbage or collard plant.

Table 2. Effect of trap cropping cabbage with collards on mean number of larvae collected per plant in Palatka, Fla., during weeks 8-13 in Spring 1998.

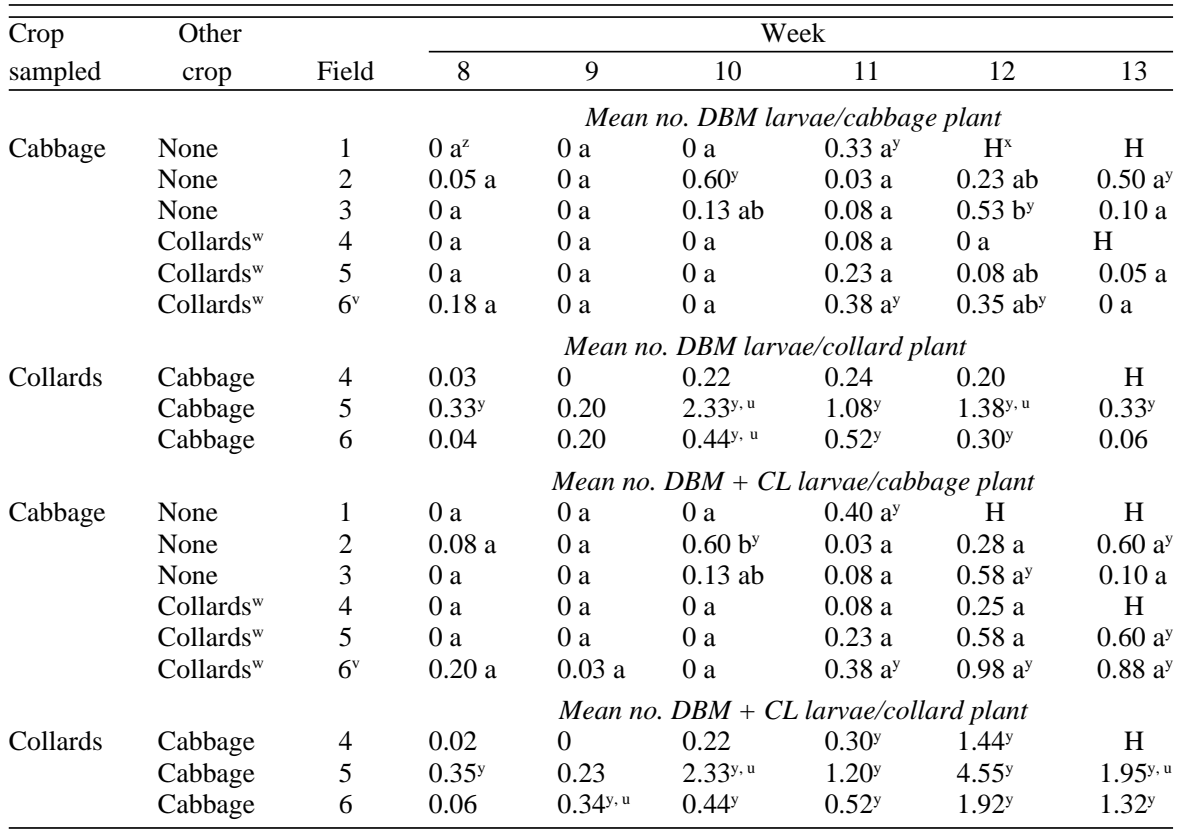

${ }^{2}$ Mean separation (Tukey-Kramer HSD) conducted on the mean number of DBM larvae/cabbage plant or $\mathrm{DBM}+\mathrm{CL}$ larvae/cabbage plant found in the six different fields; same letter following mean indicates no significant differences in larval counts at $P \leq 0.05$ during that week.

${ }^{y}$ Number of larvae at or above action threshold of 0.3 total larvae/cabbage or collard plant.

${ }^{\mathrm{w}}$ Cabbage plots were surrounded by collards in these fields.

${ }^{v}$ Field incompletely surrounded by collards.

"Mean number of larvae/collard plant significantly different from number in cabbage in the same field (i.e., Field 4, 5, or 6) using a two-sample $t$ test at $P \leq 0.05$.

${ }^{\mathrm{x}} \mathrm{H}=$ harvested.

and cabbage looper larvae, the action threshold in the cabbage was reached in a number of the fields later in the season (weeks 11-13), regardless of trap crop (Tables 2 and 3 ). The threshold in collards was reached throughout the mid-late season (weeks 8-13) in most fields.

\section{Discussion}

The results of this study indicate that planting collards along field peripheries as a trap crop may be a promising tactic to manage the DBM in commercial cabbage. In both years, the numbers of DBM larvae in collards ex- 
ceeded the action threshold of 0.3 total larvae/ plant in eight of nine fields. The numbers of DBM never exceeded the action threshold in any of the fields that were completely surrounded by collards, but did exceed the action threshold in three of the fields without collards on four sampling dates in 1998. In the fields with the trap crop, the number of pesticide applications was reduced (three vs. eight in 1997 and three vs. five or six in 1998), the numbers of DBM larvae in the cabbage were maintained under the action threshold, and the marketability of the cabbage was not reduced.

Based on the higher number of larvae on the collards than on the cabbage in both years of the study, as well as the fact that larval counts exceeding the action threshold in the collards but not in the collard-surrounded cabbage, DBM females apparently prefer to oviposit in the collards rather than in the interior cabbage. Preventing movement into the main crop by planting a more preferred trap crop is the key principle in a trap-cropping system (Hokkanen, 1991). However, the trap crops also could protect the cabbage through the conservation of the DBM's natural enemies. This may occur by a reduction in pesticide applications in the fields with the trap crop, or by attracting natural enemies to the field and concentrating them in an area of high host density, as found in other trap-cropping systems (e.g., Hokkanen, 1991; Stern, 1969). Parasitism by a host-specific natural enemy of the DBM, Diadegma insulare (Cresson) (Hymenoptera: Ichneumonidae), was higher in larvae collected in the collards than for larvae in cabbage (Mitchell et al., 1997c). Tactics such as cultural and biological control are economically and environmentally desirable within an IPM strategy (Herzog and Funderburk, 1985), so the use of trap crops to impede DBM movement into the cabbage, as well as to potentially conserve natural enemies, should be an important component in a cabbage IPM program.

Planting collard greens in the field peripheries is relatively compatible with current growing practices, which is an important consideration in determining whether a trap crop will be implemented (Hokkanen, 1991). The collards in this study were planted at the same time as the cabbage and remained healthy and continued to grow throughout the season. Had Indian mustard been used (which needs to be planted before the cabbage, then replanted later in the season) instead of collards, the growers might have been reluctant to cooperate. Srinivasan and Krishna Moorthy (1992) reported that problems associated with replanting Indian mustard limited grower implementation in their region. Another benefit of using collards instead of Indian mustard is that the trap crop itself does not require treatment with insecticide as it does the mustard. Srinivasan and Krishna Moorthy (1992) reported that Indian mustard had to be sprayed five times throughout the season to protect the cabbage. Also, the collards survived extensive larval damage, unlike Indian mustard (Bender et al., 1999).

The 1998 study was designed to be as

Table 3. Effect of trap cropping cabbage with collards on mean number of larvae collected per plant in Bunnell, Fla., during weeks 8-13 in Spring 1998.

\begin{tabular}{|c|c|c|c|c|c|c|c|c|}
\hline \multirow{2}{*}{$\begin{array}{l}\text { Crop } \\
\text { sampled }\end{array}$} & \multirow{2}{*}{$\begin{array}{l}\text { Other } \\
\text { crop }\end{array}$} & \multirow[b]{2}{*}{ Field } & \multicolumn{6}{|c|}{ Week } \\
\hline & & & 8 & 9 & 10 & 11 & 12 & 13 \\
\hline & & & \multicolumn{6}{|c|}{ Mean no. DBM larvae/cabbage plant } \\
\hline \multirow[t]{7}{*}{ Cabbage } & None & 7 & $0 \mathrm{a}^{2}$ & $0.18 \mathrm{a}$ & $0.03 \mathrm{a}$ & $0.28 \mathrm{a}$ & $0.15 \mathrm{a}$ & $0 \mathrm{a}$ \\
\hline & None & 8 & $0 \mathrm{a}$ & $0.08 \mathrm{a}$ & $0 \mathrm{a}$ & $0 \mathrm{~b}$ & $0.13 \mathrm{a}$ & $\mathrm{H}^{\mathrm{y}}$ \\
\hline & None & 9 & $0.03 \mathrm{a}$ & $0.01 \mathrm{a}$ & $0.01 \mathrm{a}$ & $0.04 \mathrm{~b}$ & $0.09 \mathrm{a}$ & $0.03 \mathrm{a}$ \\
\hline & Collards ${ }^{\mathrm{x}}$ & 10 & $0 \mathrm{a}$ & $0 \mathrm{a}$ & $0.05 \mathrm{a}$ & $0.08 \mathrm{ab}$ & $0 \mathrm{a}$ & $0.08 \mathrm{a}$ \\
\hline & Collards ${ }^{\mathrm{x}}$ & 11 & $0.03 \mathrm{a}$ & $0 \mathrm{a}$ & $0.13 \mathrm{a}$ & $0.10 \mathrm{ab}$ & $0 \mathrm{a}$ & $0.03 \mathrm{a}$ \\
\hline & Collards ${ }^{\mathrm{x}}$ & 12 & $0 \mathrm{a}$ & $0.05 \mathrm{a}$ & $0 \mathrm{a}$ & $0.10 \mathrm{ab}$ & $0 \mathrm{a}$ & $0 \mathrm{a}$ \\
\hline & & & \multicolumn{6}{|c|}{ Mean no. DBM larvae/collard plant } \\
\hline \multirow[t]{4}{*}{ Collards } & Cabbage & 10 & 0.07 & 0 & $0.43^{\mathrm{w}}$ & $1.43^{\mathrm{w}}$ & 0.20 & $1.43^{\mathrm{w}, \mathrm{u}}$ \\
\hline & Cabbage & 11 & 0 & 0.08 & $0.33^{\mathrm{w}}$ & $0.48^{\mathrm{w}, \mathrm{u}}$ & 0.10 & 0.23 \\
\hline & Cabbage & 12 & 0.05 & 0.25 & 0.25 & $0.40^{\mathrm{w}}$ & 0.10 & 0 \\
\hline & & & \multicolumn{6}{|c|}{ Mean no. $D B M+C L$ larvae/cabbage plant } \\
\hline \multirow[t]{7}{*}{ Cabbage } & None & 7 & $0 \mathrm{a}$ & $0.18 \mathrm{a}$ & $0.03 \mathrm{a}$ & $0.30 \mathrm{a}^{\mathrm{w}}$ & $0.55 \mathrm{a}^{\mathrm{w}}$ & $0.20 \mathrm{a}$ \\
\hline & None & 8 & $0 \mathrm{a}$ & $0.15 \mathrm{a}$ & $0 \mathrm{a}$ & $0.13 \mathrm{a}$ & $0.75 \mathrm{a}^{\mathrm{w}}$ & $\mathrm{H}$ \\
\hline & None & 9 & $0.05 \mathrm{a}$ & $0.04 \mathrm{a}$ & $0.04 \mathrm{a}$ & $0.23 \mathrm{a}$ & $0.34 \mathrm{a}^{\mathrm{w}}$ & $0.33 \mathrm{a}^{\mathrm{w}}$ \\
\hline & Collards ${ }^{\mathrm{x}}$ & 10 & $0.08 \mathrm{a}$ & $0.05 \mathrm{a}$ & $0.08 \mathrm{a}$ & $0.10 \mathrm{a}$ & $0.68 \mathrm{a}^{\mathrm{w}}$ & $1.18 \mathrm{a}^{\mathrm{v}}$ \\
\hline & Collards ${ }^{\mathrm{x}}$ & 11 & $0.05 \mathrm{a}$ & $0 \mathrm{a}$ & $0.15 \mathrm{a}$ & $0.10 \mathrm{a}$ & $0.03 \mathrm{a}$ & $0.18 \mathrm{a}$ \\
\hline & Collards ${ }^{\mathrm{x}}$ & 12 & $0.05 \mathrm{a}$ & $0.10 \mathrm{a}$ & $0 \mathrm{a}$ & $0.20 \mathrm{a}$ & $0 \mathrm{a}$ & $0.45 \mathrm{a}^{\mathrm{v}}$ \\
\hline & & & \multicolumn{6}{|c|}{ Mean no. DBM + CL larvae/collard plant } \\
\hline \multirow[t]{3}{*}{ Collards } & Cabbage & 10 & 0.07 & 0.03 & $0.43^{\mathrm{w}, \mathrm{u}}$ & $1.50^{\mathrm{w}}$ & 0.27 & $2.93^{\mathrm{w}}$ \\
\hline & Cabbage & 11 & 0 & 0.13 & $0.35^{\mathrm{w}}$ & $0.58^{\mathrm{w}, \mathrm{u}}$ & 0.15 & $0.60^{\mathrm{w}}$ \\
\hline & Cabbage & 12 & 0.05 & 0.25 & 0.25 & $0.40^{\mathrm{w}}$ & 0.10 & 0.05 \\
\hline
\end{tabular}

${ }^{2}$ Mean separation (Tukey-Kramer HSD) conducted on the mean number of DBM larvae/cabbage plant or $\mathrm{DBM}+\mathrm{CL}$ larvae/cabbage plant found in the six different fields; same letter following mean indicates no significant differences in larval counts at $P \leq 0.05$ during that week.

${ }^{\mathrm{y}} \mathrm{H}=$ harvested

${ }^{\mathrm{x}}$ Cabbage plots were surrounded by collards in these fields.

wNumber of larvae at or above action threshold of 0.3 total larvae/cabbage or collard plant.

"Mean number of larvae/collard plant significantly different from number in cabbage in the same field (i.e. Field 4,5 , or 6 ) using a two-sample $t$ test at $P \leq 0.05$.

extensive as possible, maximizing the number of fields and growers in different regions, while attempting to sample with as much precision as was practically feasible. A sample size of 40 plants is within the range recommended to provide acceptable precision in estimating field populations of the DBM (Harcourt, 1961), and was the minimum we sampled in most cases. If absolute population densities are much larger than those that we sampled, predicting whether collard trap crops would be an effective tactic for managing DBM would be difficult. However, populations are usually kept low in our area by using pesticides when action thresholds are approached, or when the growers otherwise feel the need to spray. If the field sizes are much smaller $(<4$ ha) or larger $(>12$ ha) than the ones we studied, predicting the efficacy of the trap crop would again be difficult. This study was designed to examine the trap crop system under the most realistic conditions as possible for our area. However, variability in grower practices or disagreement among them as to the action threshold could cause variability. We chose to use large-scale commercial fields in our study to avoid the risk of misinterpreting data when such studies are performed in unrealistically small (although well controlled and replicated) plots. The importance of documenting the results of large-scale experiments, even without ideal control and replication, has been discussed by several authors (Carpenter, 1990; George et al., 1992).

Although our data suggest that planting collard trap crops is an effective tactic to manage DBM in commercial cabbage, they do not indicate that collards function as a trap crop for the cabbage looper, another destructive pest of crucifers. Total larval counts, which included the cabbage looper, often were above the action threshold in collards as well as in cabbage (Tables 1-3). The data (which include those for loopers) show few significant differences in total larval counts between cabbage and collards, indicating again that collards are not a trap crop for loopers. The growers' motivation to spray was probably driven by the presence of loopers, so the next step in the development of cabbage IPM will involve management of the cabbage looper, using tactics that are compatible with the current program. Trap cropping with various crucifers has been an effective tactic to manage other pests of cabbage, including Hellula undalis (F.) (Lepidoptera: Plutellidae), Crocidolomia pavonana (F.) (Lepidoptera: Pyralidae), and Halticus tibialis (Reuter) (Hemiptera: Miridae) (Silva-Krott et al., 1995), and may be effective in managing the cabbage looper.

Every economic analysis that has been conducted on trap crops indicates that they substantially increase net profits to the grower (Hokkanen, 1991). Although we have not conducted a formal economic analysis on the use of collard trap crops, grower cooperators who used the system enjoyed a significant economic savings by applying fewer pesticide sprays for insect control than did growers following a conventional pest control program. A conservative estimate of costs for pesticides currently used for insect pest control in the test area is US \$35 per ha per 

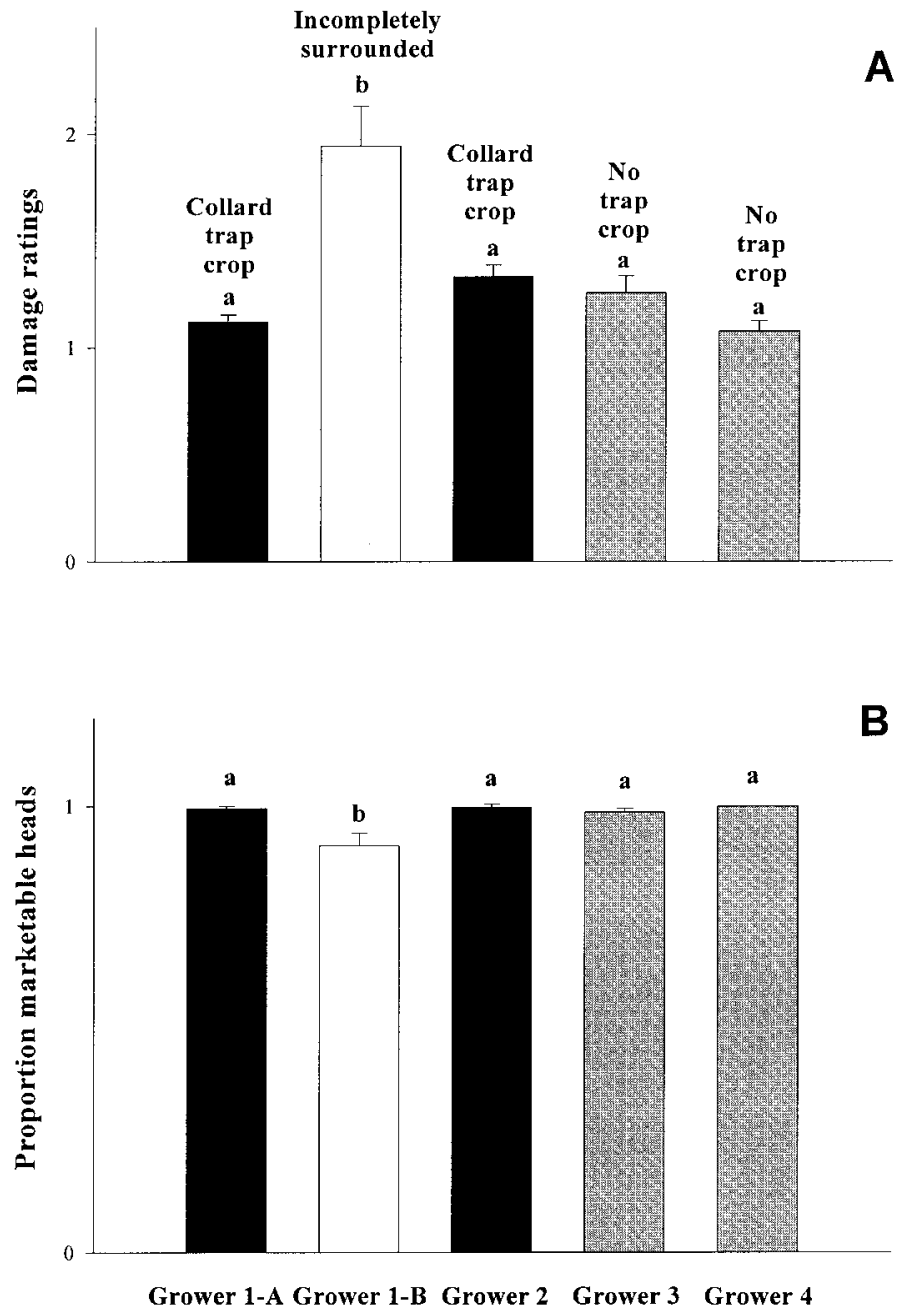

Fig. 3. Mean $( \pm \mathrm{SE})$ cabbage damage rating $(\mathbf{A})$ and proportion of marketable heads $(\mathbf{B})$ per grower in 1998. The field incompletely surrounded with collards was the only one with significantly greater damage or reduced marketability as indicated by $\mathbf{B}$ (Tukey-Kramer HSD at $P \leq 0.05$ ). However, all fields surrounded with the trap crops received fewer insecticide applications than did those with cabbage alone. Fields designated as Grower 1-A, Grower 1-B, and Grower 2 received three applications of insecticide; Grower fields 3 and 4 received five and six applications, respectively.

application. Participating growers who used the conventional approach to control insects in cabbage typically applied six to eight sprays in 1998 , costing \$210-280 per ha. Growers who used the trap crop system on average applied $56 \%$ fewer sprays, resulting in a net savings of \$117-156 per ha in pesticide costs alone. However, in very small fields there may be little economic gain to using the trap crops, since a larger proportion of the production area would have to be devoted to the collard plantings.

The growers with whom we worked were pleased with the results and have continued planting collard trap crops on their own. Based on their ability to protect interior cabbage, as well as its feasibility of implementation and acceptance by growers, we conclude that planting collards around the peripheries of cabbage can become an effective component of an IPM program for DBM.

\section{Literature Cited}

Bender, D.A., W.P. Morrison, and J.R. Kern. 1999 Intercropping cabbage and Indian mustard for po- tential control of lepidopterous and other insects. HortScience 34:275-279.

Biever, K.D., D.L. Hostetter, and J.R. Kern. 1994 Evolution and implementation of a biological control-IPM system for crucifers: A 24-year case study. Amer. Entomol. 40:103-108.

Carpenter, S.R. 1990. Large scale perturbations: Opportunities for innovation. Ecology 71:1430-1440 Composite action thresholds for the control of lepidopterous pests on fresh-market cabbage in lower Rio Grande Valley of Texas. J.Econ. Entomol. 80:175-181.

George, T.L., L.C. McEwen, and A. Fowler. 1992. Effects of a carbaryl bait treatment on nontarget wildlife. Environ. Entomol. 21:1239-1242.

Greene, G.L., W.G. Genung, R.B. Workman, and E.G Keisheimer. 1969. Cabbage looper in Florida: A cooperative program. J. Econ. Entomol. 62:798-800.

Harcourt, D.G. 1957. Biology of the diamondback moth, Plutella maculipennis (Curt.) (Lepidoptera: Plutellidae), in eastern Ontario. II. Life-history, behavior, and host relationships. Can. Entomol. 89:554-564.

Harcourt, D.G. 1961. Design of a sampling plan for studies on the population dynamics of the diamondback moth, Plutella maculipennis (Curt.) (Lepidoptera: Plutellidae). Can. Entomol. 93:820-831.
Cartwright, B., J.V. Edelson, and C. Chambers. 1987.
Herzog, D.C. and J.E. Funderburk. 1985. Plant resistance and cultural practice interactions with biological control, p. 67-88. In: M.A. Hoy and D.C. Herzog (eds.). Biological control in agricultural IPM systems. Academic, New York.

Hokkanen, H.M.T. 1991. Trap cropping in pest management. Annu. Rev. Entomol. 36:119-138.

Hu, G.Y., E.R. Mitchell, and J.S. Okine. 1997. Effect of habitat types on population densities and parasitism of the diamondback moth (Lepidoptera: Plutellidae) larvae in cabbage fields. J. Entomol. Sci. 32:56-71.

Kirsch, K. and H. Schmutterer. 1988. Low efficacy of a Bacillus thuringiensis (Berl.) formulation in controlling the diamondback moth, Plutella xylostella (L.), in the Philippines. J. Appl. Entomol. 105:249255.

Leibee, G.L. 1996. Insect pest management in crucifers in Florida, p. 413-422. In: D. Rosen, F.D. Bennett, and J.L. Capinera (eds.). Pest management in the subtropics: Integrated pest management—A Florida perspective. Intercept, Andover, U.K.

Lim, G.S. 1992. Integrated pest management of diamondback moth: Practical realities, p. 565-576. In: N.S. Talekar (ed.). Diamondback moth and other crucifer pests: Proc. 2nd Intl. Wkshp., Shunhua, Taiwan. Asian Veg. Res. Dev. Ctr.

Luther, G.C., H.R. Valenzuela, and J. Defrank. 1996. Impact of cruciferous trap crops on lepidopteran pests of cabbage in Hawaii. Environ. Entomol. 25:39-47.

Marks, R.G. 1990. Analyzing research data. Krieger Publ., Malabar, Fla.

Mitchell, E.R., G.Y. Hu, and J.S. Okine. 1997c. Diamondback moth (Lepidoptera: Plutellidae) infestation and parasitism by Diadegma insulare (Hymenoptera: Ichneumonidae) in collards and adjacent fields. Florida Entomol. 80:54-62.

Mitchell, E.R, G.Y. Hu, J.S. Okine, and J.R. McLaughlin. 1997b. Mating disruption of diamondback moth (Lepidoptera: Plutellidae) and cabbage looper (Lepidoptera: Noctuidae) in cabbage using a blend of pheromones emitted from the same dispenser. J. Entomol. Sci. 32:120-137.

Mitchell, E.R., F.C. Tingle, R.C. Navasero-Ward, and M. Kehat. 1997a. Diamondback moth (Lepidoptera: Plutellidae) parasitism by Cotesia plutellae (Hymenoptera: Braconidae) in cabbage. Florida Entomol. 80:477-489.

SAS Institute. 1990. User's guide: Statistics. Ver. 6, 4th ed. SAS Inst., Cary, N.C.

SAS Institute. 1996. JMP start statistics: A guide to statistics using JMP and JMP IN software. Duxbury Press, Belmont, Calif.

Silva-Krott, I.U.,P. Singh, T.S. Lali, and R. Muniappan. 1995. Development of a trap cropping system for cabbage in Guam. Pest Mgt. Hort. Ecosys. 1:27-35.

Srinivasan, K. and P.N. Krishna Moorthy. 1991. Indian mustard as a trap crop for management of major lepidopterous pests on cabbage. Trop. Pest Mgt. 37:26-32.

Srinivasan, K., and P.N. Krishna Moorthy. 1992. The development and adoption of integrated pest management for major pests of cabbage using Indian mustard as a trap crop, p. 10-14. In: N.S. Talekar (ed.). Diamondback moth and other cruciferous pests. Proc. 2nd Intl. Wkshp. Shunhua, Taiwan. Asian Veg. Res. and Dev. Ctr.

Stern, V.M. 1969. Interplanting alfalfa in cotton to control lygus bugs and other insect pests. Proc. Tall Timbers Conf. 1:55-69.

Tabashnik, B.E., N.L. Cushing, N. Finson, and M.W. Johnson. 1990. Field development of resistance to Bacillus thuringiensis in diamondback moth (Lepidoptera: Plutellidae). J. Econ. Entomol. 83:1671-1676.

Talekar, N.S. and A.M. Shelton. 1993. Biology, ecology, and management of the diamondback moth. Annu. Rev. Entomol. 38:275-301.

Talekar, N.S., J.C. Yang, and S.T. Lee. 1992. Introduction of Diadegma semiclausum to control diamondback moth in Taiwan, p. 263-270. In: N.S. Talekar (ed.). Diamondback moth and other crucifer pests. Proc. 2nd Intl. Wkshp., Shunhua, Taiwan. Asian Veg. Res. and Dev. Ctr. 